\title{
Identification of an HLA-A2-restricted CD147 epitope that can induce specific CTL cytotoxicity against drug resistant MCF-7/Adr cells
}

\author{
CHUANG QU ${ }^{1,2^{*}}$, SHUHUI GAO ${ }^{1,2^{*}}$, HONGWEI SHAO ${ }^{1-3}$, WENFENG ZHANG ${ }^{1-3}$, HUABBEN BO $^{1-3}, \mathrm{XIN} \mathrm{LU}^{1,2}$,

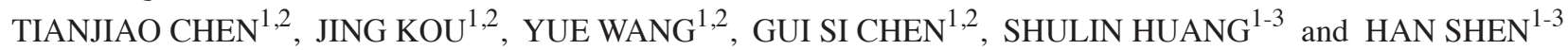 \\ ${ }^{1}$ Guangdong Province Key Laboratory of Biotechnology Drug Candidates; ${ }^{2}$ School of Life Sciences and Biopharmaceutics, \\ ${ }^{3}$ Institute of Bio-Pharmaceuticals, Guangdong Pharmaceutical University, Guangzhou, Guangdong 510006, P.R. China
}

Received November 8, 2017; Accepted January 19, 2018

DOI: $10.3892 / \mathrm{ol} .2018 .8085$

\begin{abstract}
Cluster of differentiation (CD)147 is highly expressed in drug-resistant tumor cell lines and is involved in the formation of tumor drug resistance. Therefore, immunotherapy utilizing CD147 epitope peptides is a promising approach for the elimination of drug-resistant tumor cells. However, like most tumor-associated antigens (TAAs), CD147 belongs to the autoantigen category, and T cells that recognize high affinity, immunodominant epitopes from autoantigens are deleted though thymic negative selection. Furthermore, wild-type autoantigen peptides cannot effectively activate and expand $\mathrm{T}$ lymphocytes with lower affinity $\mathrm{T}$ cell receptors in vivo. However, mutations of TAA peptides have been demonstrated to increase the affinity of major histocompatibility complex molecules and their binding to $\mathrm{T}$ cell receptor molecules, leading to activation of $\mathrm{T}$ lymphocytes in vitro. In the present study, a high-affinity point mutation peptide, $\mathrm{CD} 147_{126-134} \mathrm{~L} 2$, was predicted by the human leukocyte antigen (HLA) binding prediction algorithm and its affinity was testified using a T2 binding assay. In addition, when peptide-specific cytotoxic T lymphocytes (CTLs) were stimulated with dendritic cells loaded with the $\mathrm{CD} 147_{126-134} \mathrm{~L} 2$ peptide under HLA-A*02:01 restriction, interferon $-\gamma$ release and cytotoxicity assays showed that peptide-specific CTLs effectively cross-recognized and lysed T2 target cells loaded either with the wild-type (CD147 ${ }_{126-134}$ ) or mutated peptide (CD147 $\left.{ }_{126-134} \mathrm{~L} 2\right)$. Moreover, the CD147 ${ }_{126-134} \mathrm{~L} 2$ peptide-specific CTLs
\end{abstract}

Correspondence to: Dr Han Shen, School of Life Sciences and Biopharmaceutics, Guangdong Pharmaceutical University, 28 E. Road outside the City of Guangzhou University, Guangzhou, Guangdong 510006, P.R. China

E-mail: shenhan@gdpu.edu.cn

*Contributed equally

Key words: CD147, drug-resistance, epitope, cross-recognition, tumor-associated antigen, immunotherapy exerted strong cytotoxic activity against drug-resistant MCF-7/Adr cells, which express a high level of CD147 and are HLA-A*02:01-positive, but not against normal MCF-7 cells. Thus, this suggests that the wild-type peptide (CD147 $\left.{ }_{126-134}\right)$ is naturally presented on HLA-A*02:01 of CD147-expressing MCF-7/Adr cells and is cross-recognized by CTLs. In conclusion, an HLA-A*02:01-restricted CD147-point mutant epitope peptide was identified that induces CTLs to efficiently lyse drug-resistant MCF-7 cells that highly express CD147. Therefore, this immunotherapeutic approach should be explored as a potential treatment for drug-resistant tumors.

\section{Introduction}

Chemotherapy remains the best first line therapy for treatment of aggressive cancer. Whilst it can be effective in the short term, the high doses required can give rise to cancer cells that exhibit drug resistance, which is a major problem in current cancer treatment protocols. Recently, anti-mitotic drugs, including those targeting aurora kinases, mitotic spindle proteins and polo-like kinases, have proven disappointing underscoring the urgent need for the development of novel therapeutic strategies to overcome drug-resistance (1).

Cluster of differentiation (CD)147 (also known as EMMPRIN, basigin, M6, and tumor cell-derived collagenase stimulating factor), a glycoprotein belonging to the immunoglobulin superfamily, is enriched on the plasma membrane of tumor cells (2). The expression of CD147 is closely related to expression of the classical multi-drug resistance (MDR)-related transporter (MDR1) and its upregulation leads to a decrease in the chemosensitivity of some chemotherapeutic agents such as paclitaxel and curcumin. Studies in a variety of drug-resistant cell lines have shown that CD147 overexpression followed by RNA interference or use of anti-CD147 blocking antibodies can increase the sensitivity of tumor cells to chemotherapy drugs (3-5). Thus, overexpression of CD147 on MDR cell lines may play an important role in the resistance to chemotherapy drugs and CD147 is considered a potential therapeutic target (6). While antibodies against CD147 have been screened for cancer treatment, cell immunotherapy using CD147 as a target has yet to be explored. Therefore, in this study we 
investigate whether drug resistance can be overcome by targeting CD147 expressed on drug-resistance cells.

Cell immunotherapy represents a profound shift in the treatment of cancer and because it is a specifically targeted therapy it provides the possibility of fewer side effects compared to chemotherapy $(7,8)$. Moreover, an optimal target can be identified for treatment of resistant tumor cells and cell immunotherapy applied for their removal. For example, generation of CD147-peptide specific reactive CTLs can be achieved using dendritic cells (DCs) loaded with the CD147 TAA peptide. However, some clinical trials have indicated that TAA peptide vaccines designed with tumor-associated antigen (TAA) fail to achieve a satisfactory effect in vivo. This may be owing to central and peripheral immune tolerance making activation and expansion of low affinity $\mathrm{T}$ cells difficult in vivo. Therefore, strategies to modify the CD147 peptide in order to enhance its binding to MHC and boost affinity of the peptide MHC complex for the TCR thereby inducing peptide-specific CTL activation and expansion in vitro are necessary (9).

Based on these findings, we believe CD147 could be a optimal target of $\mathrm{CD}^{+}$cytotoxic $\mathrm{T}$ lymphocytes (CTLs). However, TAA peptide vaccine designed directly with TAA failed to achieve a satisfactory effect in vivo (10). This may owing to the central and peripheral tolerance, it also make low affinity $\mathrm{T}$ cell difficult to be activate and expansion. Therefore, strategies should be taken to modify CD147 epitope peptide enhance its affinity to MHC molecule in order to boost the affinity of the peptide MHC complex to the TCR, thus leading peptide specific CTL activation and expansion in vitro. In our previous study, a mutated survivin epitope, identified by point mutation, could elicit specific CTL with crossreactivity against tumor cells expressing a wild-type survivin peptide in vitro $(11,12)$.

In our previous study, we identified a point mutation in the survivin epitope that could elicit a specific CTL response in vitro with cross-reactivity against tumor cells expressing a wild-type survivin peptide. In this study, we identified CD147 ${ }_{126-134}$, a low binding score wild-type peptide, using a computer-based program and then used point-mutation technology to substitute the $\mathrm{L}(\mathrm{leu})$ at position 2 of the wild-type peptide with $\mathrm{K}$ (lys), to generate a peptide capable of inducing specific CTLs. We found that these CTLs could recognize and lyse the wild-type CD147 ${ }_{126-134}$ peptide expressed on the surface of drug-resistant cells.

\section{Materials and methods}

Cells and cell culture. The T2 cell line was purchased from ATCC and maintained in RPMI 1640 with 10\% FBS (both Gibco; Thermo Fisher Scientific, Inc., Waltham, MA, USA), $100 \mathrm{IU} / \mathrm{ml}$ penicillin, $100 \mathrm{~g} / \mathrm{ml}$ streptomycin (both Sigma-Aldrich, Madrid, Spain). The MCF-7 (HLA-A*0201+, CD147 ${ }^{+}$, , SKOV3 (HLA-A*0201+, CD147-), Hela (HLA-A*0201CD147 ${ }^{+}$) was cultured in DMEM (Life Technologies, New York, NY, USA) containing 10\% FBS, $100 \mathrm{IU} / \mathrm{ml}$ penicillin, $100 \mathrm{~g} / \mathrm{ml}$ streptomycin. The SKOV3 cell line was transfected with expression vector pcdna3.1 containing HLA-A*0201 cDNA. The MCF-7/Adr (HLA-A*0201 $\left.{ }^{+}, \mathrm{CD} 147^{+}\right)$cell line was cultured in DMEM supplemented with $10 \%$ FBS with $1 \mu \mathrm{g} / \mathrm{ml}$ Adriamycin (Selleck, Shanghai, China) (13). K562 cell line purchased from ATCC were used as natural killer cell-sensitive targets. K562 were cultured in IMDM (Gibco; Thermo Fisher Scientific, Inc.) supplemented containing 10\% FBS, $100 \mathrm{~g} / \mathrm{ml}$ streptomycin, $100 \mathrm{IU} / \mathrm{ml}$ penicillin.

Peptide epitope prediction and synthesizing. The sequences of CD147 was obtained from GenBank and analyzed for HLA-A*0201 binding motifs using BIMAS (http://www-bimas. cit.nih.gov/molbio/hla_bind/) and SYPEITHI (www. syfpeithi.de) (14). The wild-type peptide, CD147 $126-134$, and mutated peptide, CD147 ${ }_{126-134} \mathrm{~L} 2$, were selected for additional evaluation. The HIVpol H76-484 $_{\text {was }}$ used as a positive control for HLA-A*0201 binding ability. The $\mathrm{HIVpol}_{476-484}$ peptide was used as an irrelevant peptide to assess cytotoxicity in a Calcein-AM release assay. All peptides were synthesized by Chinapeptide (Shanghai, China) and the purity was detected to an average of approximately 98 percent by analytical mass spectrometry and high performance liquid chromatography. Peptides were dissolved at $10 \mathrm{mg} / \mathrm{ml}$ in DMSO (Sigma, St Louis, MO, USA) and stored at $-70^{\circ} \mathrm{C}$ for long-term preservation. All peptides are list in Table I.

Peptide-binding assay. A peptide-induced stabilization assay was performed using the T2 cell line expressing the HLA A*0201 molecule (15). Briefly, T2 cells (1x10\%/group) were incubated in the presence of $20 \mu \mathrm{g} / \mathrm{ml}$ peptide in AIMV medium (Gibco; Thermo Fisher Scientific, Inc.) supplemented with $5 \mu \mathrm{g} / \mathrm{ml}$ human $\beta 2$-microglobulin (Sigma-Aldrich, Spain) at $37^{\circ} \mathrm{C}$ in $5 \% \mathrm{CO}_{2}$ for $18 \mathrm{~h}$. T2 cells were washed twice with PBS to remove unbound peptide and resuspended in PBS containing $2 \%$ FBS. T2 cells loaded with peptide were incubated with FITC-conjugated HLA-A2 monoclonal antibody (BB7.2; BioLegend, San Diego, CA, USA). The expression level of HLA-A*0201 was measured using flow cytometry (Beckman Coulter, Miami, FL, USA) and the EXPO32 v1.2 software was used to analyze the results.

Flow cytometric analysis of CD147 expression. Cells ( $1 \times 10^{6}$ cells/group) were washed with PBS two times followed by resuspension in PBS with 2\% FBS. Cells then were then incubated for $30 \mathrm{~min}$ at $4^{\circ} \mathrm{C}$ with FITC-conjugated monoclonal anti-CD147 antibody (BD Biosciences, San Diego, CA USA) or FITC-conjugated anti-mouse IgG1 isotype control antibody (BD Biosciences). After two washes with PBS, cells were resuspended in PBS to measure expression of CD147 by the flow cytometry and the EXPO32 v1.2 software was used to analyze the results.

Induction of peptide-specific CTLs. All subjects in this study were Han Chinese from Guangdong province, China, and all gave a written informed consent. This study was performed with the approval of the Institute Research Medical Ethics Committee of Guangzhou Pharmaceutical University. PBMCs used were isolated from buffy coats obtained from healthy HLA-A*0201 volunteer donors. Adherent monocyte-enriched PBMCs were maintained in X-VIVO (Lonza, Benicia, CA, USA) in the presence of $10 \mathrm{ng} / \mathrm{ml}$ recombinant human IL-4 and 1,000 U/ml recombinant human GM-CSF (both from Peprotech, London, UK). Half of the medium was replaced every 3 days. After 6 days, $10 \mathrm{ng} / \mathrm{ml}$ tumor necrosis factor- $\alpha$ (TNF- $\alpha)$ was added 
Table I. Predicted CD147 peptides.

\begin{tabular}{lccrc}
\hline Peptide name & Position & Amino acid sepuence & BIMAS score & SYFPEITHI score \\
\hline CD147 & $126-134$ & CKSESVPPV & 0.911 & 17 \\
CD147 $_{126-134} \mathrm{~L}^{\mathrm{a}}$ & $126-134$ & CLSESVPPV & 655.875 & 27 \\
$\mathrm{HIVpol}_{476-484}$ & $476-134$ & ILKEPVHGV & 39.025 & 30
\end{tabular}

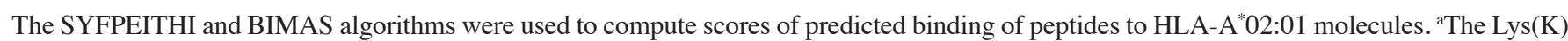
residue at position 127 is mutated to Leucine (L). BIMAS, Behavior Intervention Monitoring Assessment System; CD, cluster of differentiation.

to the culture. On day 10, all mature DCs were collected, and partly mature DCs (1x10 $/$ group) were loaded with $20 \mu \mathrm{g} / \mathrm{ml}$ peptide at $37^{\circ} \mathrm{C}$ in $5 \% \mathrm{CO}_{2}$ for $4 \mathrm{~h}$. DCs ( $1 \times 10^{5} /$ group) loaded with peptide were cocultured with PBLs (1x10\%/group) plated at a 1:10 ratio in $2 \mathrm{ml} \mathrm{X-VIVO} \mathrm{medium} \mathrm{containing} \mathrm{10 \%} \mathrm{FBS}$ in 6-well plates, and $5 \mathrm{ng} / \mathrm{ml} \mathrm{IL-2,5} \mathrm{ng/ml} \mathrm{IL-} 15$, and $10 \mathrm{ng} / \mathrm{ml}$ IL-7 (all from Peprotech) were added after $24 \mathrm{~h}$. Half of the medium was replaced with media containing fresh cytokines every 3 days. Seven days later, the CTLs were reticulated with DCs loaded with peptide. After 3 cycles of reticulation, an ELISPOT (Dakewe, ShenZhen, China) assay and Calcein-AM release assay for cytotoxicity were performed.

ELISPOT assay. A human IFN- $\gamma$ ELISPOT assay kit was used to determine the function of the CTLs, according to the manufacturer's instructions. CTLs induced by peptide CD147 ${ }_{126-134}$ and CTLs induced by CD147 ${ }_{126-134} \mathrm{~L} 2$ were used as the effector cells. T2 cells loaded with or without peptide were used as target cells. Effector cells were incubated in duplicate for $18 \mathrm{~h}$ at $37^{\circ} \mathrm{C}$ with target in a 96-well ELISPOT plate coated with anti-human IFN- $\gamma$ antibody. A positive control (PHA) and a negative control ( $\mathrm{HIVpol}_{476-484}$ peptide) were included in all assays. Biotinylated antibody, streptavidin-enzyme conjugate and the enzyme substrate nitroblue tetrazolium was added to the plates in order, followed by a thirty-minute incubation at room temperature. Images of spots were captured by using a dissection microscope, then counted using Image Master Total Lab v1.10 software (Amersham Biosciences, Uppsala, Sweden).

Cytotoxicity calcein-AM release assay. To measure the cytotoxic response of the CTLs induced by target cells with different peptides, a calcein AM (Nippon Chemical Research TongRen Institute, Japan) release-based cytotoxic assay was performed as described previously. MCF-7, MCF-7/Adr, Hela, SKOV3, K562 and T2 loaded with or without peptide were used as target cells. CD147 $7_{126-134}$-CTLs and CD147 ${ }_{126-134}$ L2-CTLs were used as the effector cells. An irrelevant peptide, $\mathrm{HIV}_{476-484}$, was used as a negative control. T2 cells were loaded with or without peptide for $4 \mathrm{~h}$ at $37^{\circ} \mathrm{C}$ in $5 \% \mathrm{CO}_{2}$ and washed thrice. Target cells were labeled with Calcein-AM for $25 \mathrm{~min}$ at $37^{\circ} \mathrm{C}$ in $5 \% \mathrm{CO}_{2}$ and then calcein-AM-labeled target cells were cocultured with effectors at different ratios (E:T=10:1, 20:1, 40:1) in 96-well-U-bottomed plates (Guangzhou Jet Bio-Filtration Co., Ltd., Guangzhou, China). After incubation for $4 \mathrm{~h}$ at $37^{\circ} \mathrm{C}$ in $5 \% \mathrm{CO}_{2}$, cell-free supernatant was analyzed using a Microplate Reader (Thermo Fisher Scientific, Inc.) with excitation at
$485 \mathrm{~nm}$ and emission at $535 \mathrm{~nm}$. In blocking experiments, T2 cells loaded with peptide or tumor cell lines were preincubated with $10 \mu \mathrm{g} / \mathrm{ml}$ anti-HLA-A2 antibody (BB7.2: mouse IgG2a) or isotype control antibody (L243: mouse IgG2a) for $1 \mathrm{~h}$. Each assay was performed in triplicate. The percentage of specific lysis was determined as: $\left(\mathrm{OD}_{\text {experimental release }}{ }^{-}\right.$ $\left.\mathrm{OD}_{\text {spontaneous release }}\right) /\left(\mathrm{OD}_{\text {maximal release }}-\mathrm{OD}_{\text {spontaneous release }}\right) \times 100$. The labeled targets in the spontaneous release well were incubated with $2 \%$ Triton X-100 and the labeled targets in the maximum release well were incubated with medium alone.

Statistical analysis. Statistical analysis was performed using GraphPad Prism 5 software (GraphPad Software, La Jolla, CA, USA). All results are expressed as the mean \pm SEM and statistical analyses were performed using the Student's t-test. $\mathrm{P}<0.05$ was considered to indicate a statistically significant difference and ns, no statistical significance.

\section{Results}

Expression of CD147 in drug-resistant and drug-sensitive cell lines. Flow cytometry was used to compare the surface expression of CD147 on drug-resistant and drug-sensitive cell lines. drug-resistant cell lines MCF-7/Adr (90.6\%) expressed a higher level than drug-sensitive MCF-7 (27.3\%) or Hela drug-sensitive cell lines (40.0\%) (Fig. 1).

Identification of CD147 peptide candidates. We first screened for a low affinity epitope peptide from the CD147 protein sequence and position 2 is a hydrophilic amino acid followed by substitution with a hydrophobic amino acid. CD147 $126-134$ and CD147 ${ }_{126-134}$ L2 peptides were identified from candidate HLA-A*0201 CD147 epitopes using two different HLA-peptide-binding prediction programs, BIMAS and SYFPEITHI. In CD147 ${ }_{126-134} \mathrm{~L} 2$ the $\mathrm{Lys}(\mathrm{K})$ at position 2 of CD147 ${ }_{126-134}$ is substituted with (L)leu. As shown in Table I, mutated peptide $\mathrm{CD} 147_{126-134} \mathrm{~L} 2$ showed significantly higher binding to the HLA-A*0201 molecule compared with the wild-type CD147 $7_{126-134}$. Moreover, this binding was even higher than the positive control peptide, HIVpol $_{476-484}$, which was generated from the HIV pol protein and was previously reported to have high binding affinity for the HLA-A"0201.

MHC stabilization assay. A T2 cell peptide-binding test was used to evaluate the binding ability of mutated peptides to HLA-A*0201 molecules. Because peptide binding to HLA-A2 molecules can increase the expression of HLA-A*0201 

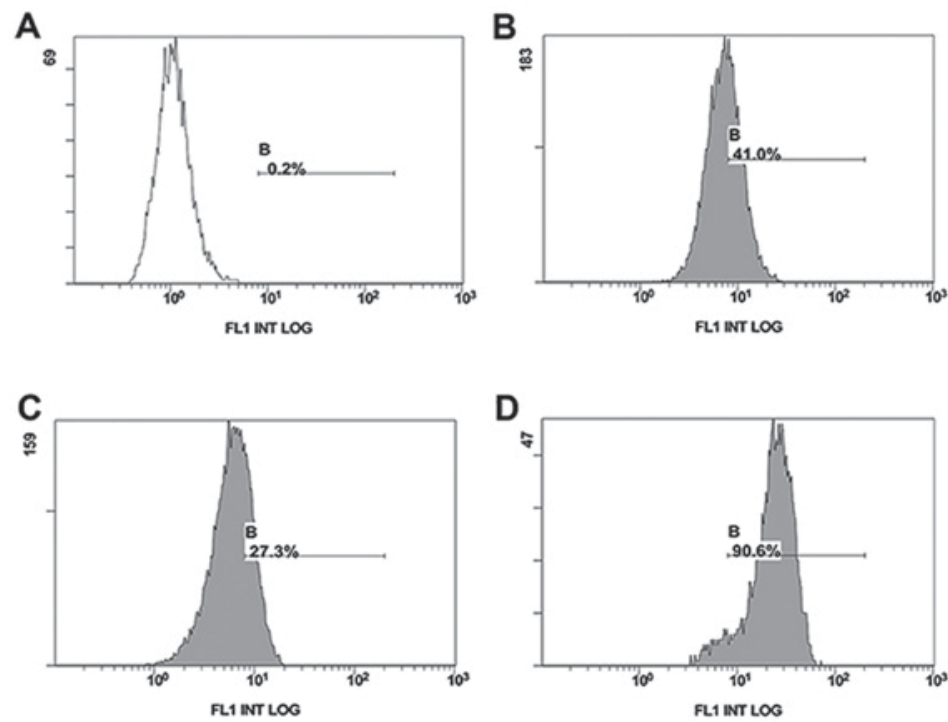

Figure 1. CD147 expression on the surface of several tumor cell lines including, SKOV3, Hela, MCF-7, and MCF-7/Adr. (A) SKOV3, the CD147-negative control cell line and (B) the HLA-A2-negative control Hela cell line, (C) the MCF-7 cell line and (D) MCF7/Adr cell line were analyzed using flow cytometry with the anti-HLA-A2 antibody, BB7.2. CD, cluster of differentiation; HLA, human leukocyte antigen.

molecules, high affinity peptides can significantly upregulate HLA-A*0201 compared to low affinity peptides. As shown in Fig. 2, the CD147 ${ }_{126-134} \mathrm{~L} 2$ (Fig. 2D) peptide induced an increase in cell surface HLA-A*0201 stabilization compared to the positive control, $\mathrm{HIVpol}_{476-484}$ peptide (Fig. 2C). In contrast, the wild-type peptide CD147 ${ }_{126-134}$ (Fig. 2B) showed no increase over background (T2 cells without peptide) (Fig. 2A). Thus, the high binding score of the mutated CD147 $7_{126-134} \mathrm{~L} 2$ peptide correlates with high affinity to HLA-A*0201 molecules, as demonstrated by this MHC stabilization assay. These results suggest that the mutated $\mathrm{CD} 147_{126-134} \mathrm{~L} 2$ peptide may be more immunogenic than the wild-type CD147 $126-134$ peptide.

CD147 reactive CTLs can lyse peptide-pulsed $T 2$ target cells. Previous studies have shown that a variety of known CTL epitopes exhibit high to intermediate affinity binding to HLA class I molecules and have the capacity to induce peptide-specific CTL responses. Therefore, to investigate the antigen specificity of peptide-induced CTLs, we evaluated their ability to secrete IFN- $\gamma$ in response to target cells. To this end, T2 cells pulsed with the mutated CD147 ${ }_{126-134} \mathrm{~L} 2$ or wild-type CD147 $7_{126-134}$ peptide were used as targets in IFN- $\gamma$ ELISPOT and cytotoxicity assays.

In the IFN- $\gamma$ ELISPOT assay, CD147 ${ }_{126-134} \mathrm{~L} 2$ was found to prime significantly more epitope-specific CTLs than CD147 $126-134$ (Fig. 3). In addition, the frequencies of IFN- $\gamma$ producing $\mathrm{T}$ cells induced by $\mathrm{CD} 147_{126-134} \mathrm{~L} 2$ was markedly increase compared to the negative control. Importantly, when T2 cells were loaded with wild-type CD147 ${ }_{126-134}$ peptide, the mutated $\mathrm{CD} 147_{126-134} \mathrm{~L} 2$ peptide-induced CTLs still possessed the capacity for IFN- $\gamma$ secretion at a level equivalent to coculturing with $\mathrm{T} 2$ cells pulsed with CD147 ${ }_{126-134}$ L2 (Fig. 3A). In contrast, T2 cells loaded with CD147 $7_{126-134}$ elicited minimal IFN- $\gamma$ secretion and induced only negligible T-cells responses (Fig. 3B). Further, T2 cells loaded with wild-type CD147 $7_{126-134}$ peptide could be lysed by the CTLs induced by CD147 ${ }_{126-134} \mathrm{~L} 2$. Also,

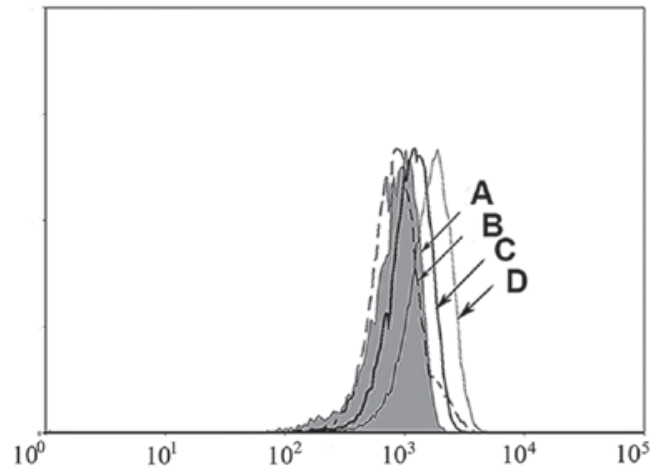

Figure 2. HLA stabilization assay using T2 cells. Flow cytometric analysis of the levels of HLA-A2 on T2 cells without peptide (A, grey histogram) or with $\mathrm{CD}_{147_{126-134}}$ (B, dashed line), $\mathrm{HIVpol}_{476-484}$ as a positive control (C, heavy solid line) and CD147 $126-134$ L2 (D, thin solid line). Peptides were tested at $20 \mu \mathrm{g} / \mathrm{ml}$. The results are representative of at least three independent experiments. CD, cluster of differentiation; HLA, human leukocyte antigen.

CTLs induced by CD147 $7_{126-134} \mathrm{~L} 2$ could efficiently lyse CD147 ${ }_{126-134} \mathrm{~L} 2$ peptide-loaded T2 cells, but did not irrelevant peptide $\mathrm{HIVpol}_{476-484}$ peptide-loaded T2 cells at any effector-target ratio (Fig. 3C). In addition, CTLs induced by CD147 ${ }_{126-134}$ only secrete a small amount of IFN- $\gamma$ against CD147 $126-134$ or CD147 ${ }_{126-134}$ L2-loaded T2 cells (Fig. 3D). These results demonstrate that the mutated CD147 ${ }_{126-134} \mathrm{~L} 2$ peptide can elicit CTLs that have the ability to cross-recognize and specifically lyse $\mathrm{T} 2$ cells loaded with the wild-type CD147 $7_{126-134}$ peptide.

CD147 peptide-specific CTLs recognize CD147 positive MCF-7/ADR cells, but not CD147 negative tumor cells. We found that $\mathrm{CD} 147_{126-134} \mathrm{~L} 2$ peptide-specific CTLs can efficiently recognize wild-type peptide-pulsed $\mathrm{T} 2$ cells and this recognition leads to the production of IFN- $\gamma$. Next, to investigate if these CTLs can lyse wild-type CD147 peptide naturally presented 
A

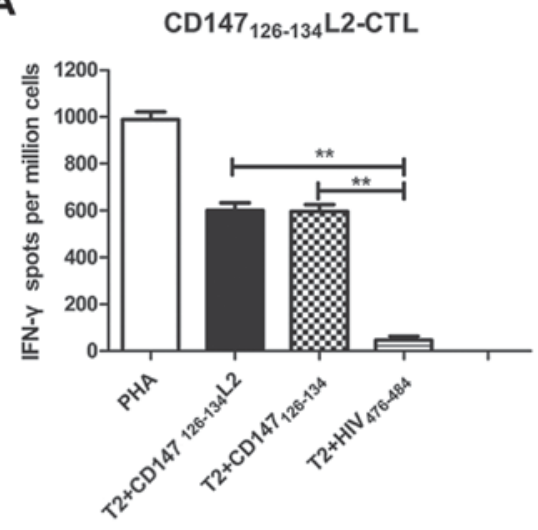

C

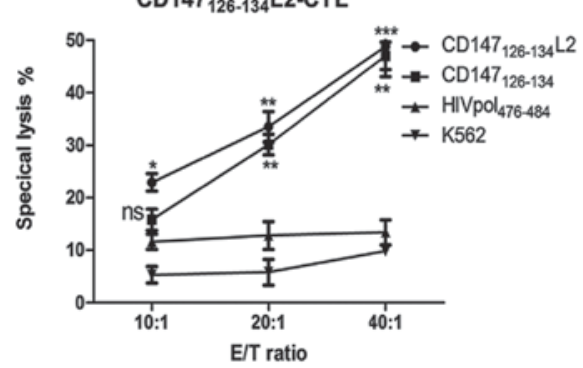

B

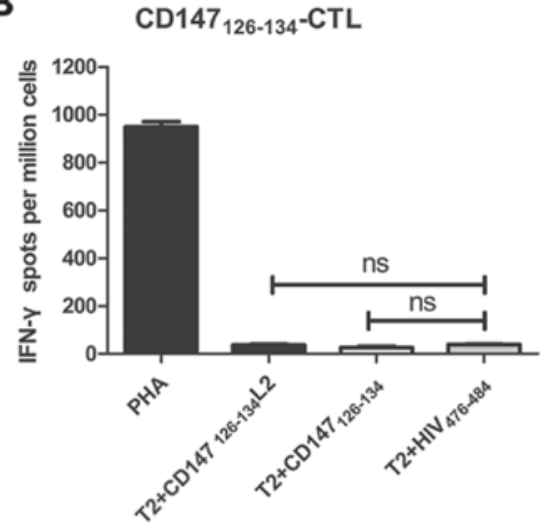

D

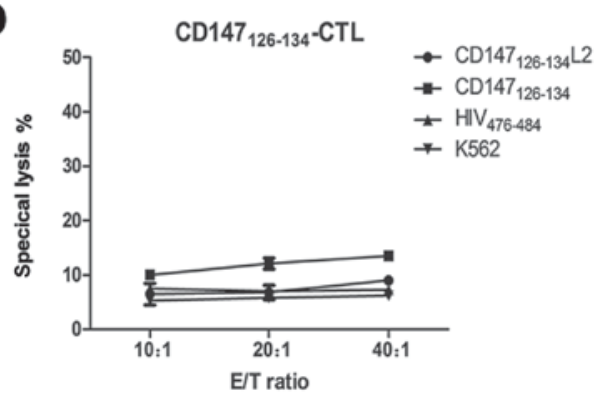

Figure 3. Induced CTLs were tested for their capacity to lyse T2 cells loaded with the cognate peptide or the irrelevant $\mathrm{HIVpol}_{476-484} \mathrm{Peptide}_{\text {. (A) CD147 }}$ 126-134 $\mathrm{L} 2$ and (B) CD147 ${ }_{126-134}$-specific human CTLs were tested for their capacity to respond to T2 target cells loaded with cognate peptide or the irrelevant HIVpol $\mathrm{H}_{476-484}$ peptide by IFN- $\gamma$ ELISPOT assay. An effector to target ratio of 20:1 was used. (C) CD147 126-134 $^{2}$ 2 and (D) CD147 $7_{126-134}$ peptide-specific human CTLs were examined for reactivity against $\mathrm{T} 2$ cells pulsed with the corresponding peptides or control $\mathrm{HIVpol}_{476-484}$ peptide $(20 \mu \mathrm{g} / \mathrm{ml})$ at different effector to target ratios by Calcein-AM release assay. Irrelevant $\mathrm{HIVpol}_{476-484}$ peptide was used as a negative control. Experiments were repeated three times. Data represented mean \pm SD. ${ }^{*} \mathrm{P}<0.05,{ }^{* * *} \mathrm{P}<0.01,{ }^{* * *} \mathrm{P}<0.001$, compared with negative control $\mathrm{HIVpol}_{476-484}$ peptide group. CTL, cytotoxic T lymphocytes; CD, cluster of differentiation; HLA, human leukocyte antigen.

on tumor cells, we used the MCF-7 (HLA-A*0201+, CD147 ${ }^{\text {low }}$ ) and the MCF-7/Adr (HLA-A $0201^{+}, \mathrm{CD} 147^{\text {hight }}$ ) cell lines as target cells, and the SKOV3 (HLA-A*0201 ${ }^{+}, \mathrm{CD} 147^{-}$) and Hela (HLA-A*0201', CD147+) cell lines were included as negative controls. Target cells were seeded and cocultured with the CD147 ${ }_{126-134} \mathrm{~L} 2$ peptide-specific CTLs at different effector to target ratios for $4 \mathrm{~h}$ at $37^{\circ} \mathrm{C}$ in $5 \% \mathrm{CO}_{2}$. As shown in Fig. 4A, CD147 ${ }_{126-134}$ L2-specific CTLs can lyse both MCF-7 and MCF-7/Adr drug-resistance cell lines, but only minimally lysed the HLA-A*0201-negative (Hela) and CD147-negative (SKOV3) lines at any effector to target ratio (Fig. 4A). In contrast, the cytotoxic effect on the MCF-7/Adr (HLA-A*0201+, $\mathrm{CD} 147^{\text {hight }}$ ) cell line was dramatically increased (approximately 40.6\%) at E:T=40:1 (Fig. 4A). In addition, CTLs induced by wild-type peptide $\mathrm{CD} 147_{126-134}$ showed only a very weak effect on MCF-7/Adr cells (HLA-A*0201+, CD147 ${ }^{\text {hight }}$ ) (Fig. 4B).

These results illustrate two points: i) the wild-type CD147 ${ }_{126-134}$ peptide can be naturally processed and presented by tumor cells, and ii) CD147 epitopes processed and presented on tumors can be cross-recognized and lysed by CD147 ${ }_{126-134} \mathrm{~L} 2$-specific CTLs. Furthermore, these experiments indicate that the low level of CD147 expression on drug-free tumor cells is not easily recognized and lysed by CD147 ${ }_{126-134} \mathrm{~L} 2$ peptide-specific CTLs. Interestingly, flow cytometry revealed that the CD147 expression level on MCF-7/Adr cell lines was higher than that of the MCF-7 cell line, which may explain the higher sensitivity of these cells to lysis.
Antibody inhibition assay. To confirm whether the reactivity of CD147 ${ }_{126-134} \mathrm{~L} 2$ peptide-specific CTLs was restricted by the HLA-A2, an antibody blocking assay was performed and calcein-AM release used as a readout. For these experiments, the MCF-7/Adr cell line and peptide-pulsed T2 cells were used as target cells. The specific lysis of CD147 ${ }_{126-134}$ L2-induced CTLs incubated with T2 cells loaded with wild-type CD147 ${ }_{126-134}$ peptide or mutated CD147 ${ }_{126-134} \mathrm{~L} 2$ peptide was blocked by anti-HLA-A2 antibody, but not by the isotype control antibody, as shown in Fig. 4C. In addition, when anti-HLA-A2 antibody was added to the cytolytic assay, the specific lysis of the MCF-7/Adr drug-resistant cell line by CD147-specific CTLs dropped below 5\% (Fig. 4C). These results indicate that the $\mathrm{CD} 147_{126-134} \mathrm{~L} 2$ peptide-induced CTLs recognize and lyse cells expressing the mutated peptide or the wild-type peptide both in an antigen-specific and HLA-A*0201-restricted manner.

\section{Discussion}

Chemotherapy plays an important role in treatment of cancer patients; however, the long-term use of chemotherapeutic drugs can result in MDR and death. Moreover, there has not been significant progress toward reducing multidrug resistance-induced morbidity and mortality despite myriad advances in treatment options $(16,17)$. The targeting of drug-resistance cells using cell-based immunotherapy is a 
A

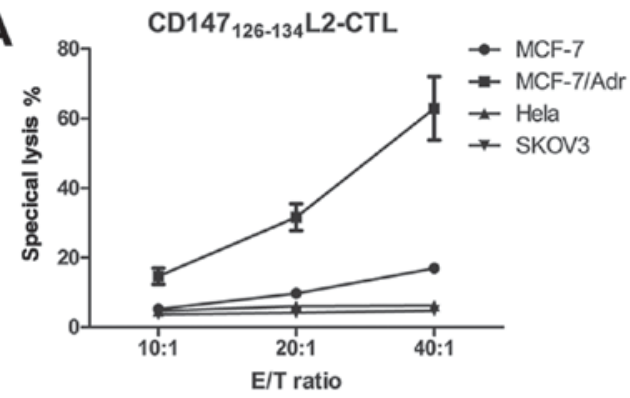

C

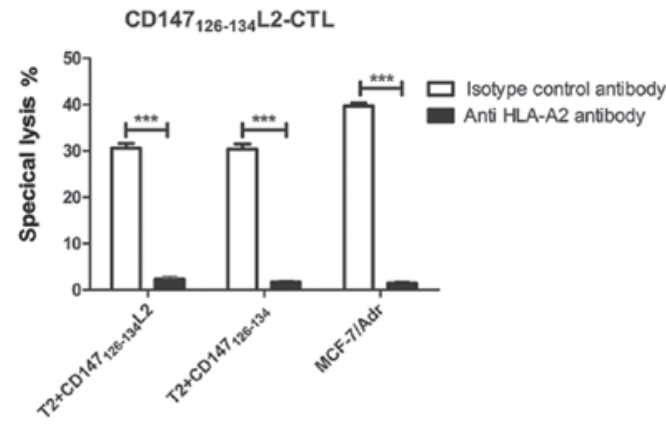

B

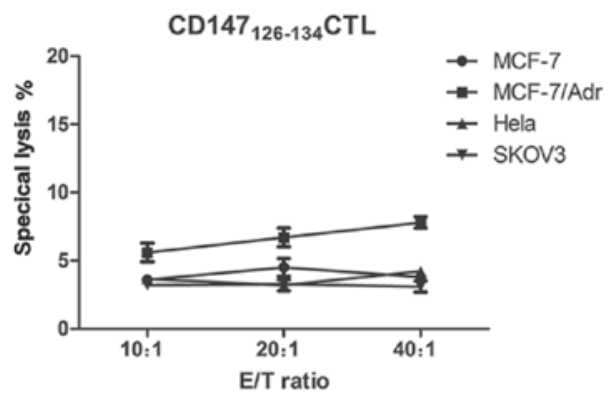

Figure 4. Specific lysis of various tumor cell lines by CTLs generated against DCs pulsed with different peptides. A cytotoxic calcein-AM release assay

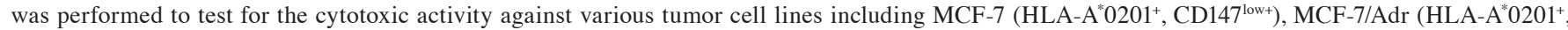

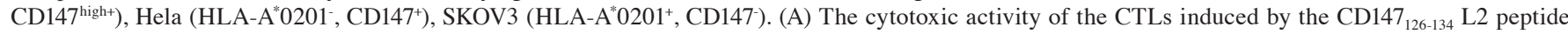
was assessed against different target cells at various E:T ratios. (B) wild-type peptide CD147 $7_{126-134}$ induced CTLs were cocultured with target cells at different effector to target ratios for $4 \mathrm{~h}$ to test the cytotoxicity. (C) MCF-7/Adr and T2 cells pulsed with CD147 ${ }_{126-134} \mathrm{~L} 2$ peptide were treated with $10 \mu \mathrm{g} / \mathrm{ml}$ anti-HLA A2 antibody or isotype control antibody for $1 \mathrm{~h}$. A calcein-AM release assay was performed to demonstrate the cytotoxic activity of the effector cells generated from the HLA-A*0201 donor against these target cells 20:1. Data are represented as mean $\pm \mathrm{SD}$. ${ }^{* * *} \mathrm{P}<0.001$, compared with isotype control group. CTL, cytotoxic T lymphocytes; CD, cluster of differentiation; HLA, human leukocyte antigen.

relatively new strategy that shows promise towards overcoming multidrug resistance (18).

CD147 is overexpressed in many MDR cell lines, and the association between its expression and resistance to chemotherapeutic drugs has been well established. For example, Toole and Slomiany (19) found that the interaction of CD147 with CD44 and hyaluronan can co-regulate MDR to anticancer drugs. Many approaches have been used to deplete drug-resistance cells such as use of an anti-CD147 antibody to inhibit tumor cell proliferation in vivo in a mouse model (20). However, the limitation with antibody treatments is that often only a small amount of antibody can penetrate into the tumor tissue, so that antibody therapy in the body is less effective than in vitro. The overexpression of CD147 in chemoresistant cells makes this molecule an ideal target for cell immunotherapy that specifically targets cells that survive chemotherapy.

$\mathrm{T}$ cells recognizing high affinity, immunodominant epitopes from self-antigens are deleted in the thymus thereby leading to immune tolerance. $\mathrm{T}$ cells that recognize low affinity epitopes are difficult to be activated. Great effort has been spent in recent years to design anchor-modified peptides in order to overcome the failure of activation of $\mathrm{T}$ cells that recognize low affinity epitopes (21). Engels et al demonstrated that the affinity of peptides and MHC molecules is particularly critical for peptide cross-presentation and induction of cytokine production in vivo (22). Thus, peptides that exhibit higher affinity for MHC molecules may create a peptide-MHC complex which can interact more efficiently with the peptide-specific TCR (23). In this study, flow cytometric analysis revealed that CD147 is overexpressed on drug-resistance cells, which is consistent with other research. Therefore, we screened the CD147 protein sequence to identify a low-binding score peptide using HLA-peptide-binding prediction software and identified CD147 ${ }_{126-134}$. We then replaced the primary anchor residue, Lys $(\mathrm{K})$, in position 2 with leu $(\mathrm{L})$, resulting in a peptide with a very high binding score (CD147 $\left.{ }_{126-134} \mathrm{~L} 2\right)$. Moreover, the T2 affinity assay clearly showed that CD147 ${ }_{126-134} \mathrm{~L} 2$ has strong binding capacity compared with the positive control (HIVpol $_{476-484}$ ) and wild-type CD147 ${ }_{126-134}$ peptide.

In vitro priming and expansion of the CD147 peptide-specific CTLs was clearly shown by IFN- $\gamma$ Elispot. These studies also showed that the CD147 ${ }_{126-134} \mathrm{~L} 2$ peptide-specific CTLs secrete markedly more IFN- $\gamma$ in response to T2 cells loaded with $\mathrm{CD} 147_{126-134} \mathrm{~L} 2$ than with CD147 $126-134$. Moreover, the CD147 ${ }_{126-134}$ L2-stimulated CTLs cocultured with CD147 ${ }_{126-134}$ loaded T2 cells also showed a similar level of IFN- $\gamma$ secretion. Cytotoxicity assays were performed by coculturing the CD147 ${ }_{126-134} \mathrm{~L} 2$ or $\mathrm{CD}_{147_{126-134}}$ peptide-primed CTLs with peptide-pulsed T2 target cells. The results showed that CTLs induced by CD147 ${ }_{126-134} \mathrm{~L} 2$ can not only lyse T2 cells loaded with CD147 ${ }_{126-134} \mathrm{~L} 2$, but also those loaded with wild-type CD147 $7_{126-134}$ peptide. In contrast, the CTLs induced by CD147 ${ }_{126-134}$ showed a very weak cytotoxicity to the CD147 ${ }_{126-134}$ or CD147 ${ }_{126-134} \mathrm{~L} 2$ peptide loaded T2 cells. Although there is a single amino acid difference between the mutated and original peptides, CTLs induced by the mutated peptide can cross-recognize wild-type peptide, as was verified by our T2 target cell experiment.

Next we used tumor cells as target cells to verify our hypothesis, and found that HLA-A2 positive MCF-7/Adr 
cells, which highly express CD147, can be specifically recognized and lysed by the CTLs induced by CD147 ${ }_{126-134} \mathrm{~L} 2$. In contrast, Hela cells $\left(\mathrm{HLAA} 2, \mathrm{CD} 147^{+}\right.$) and SKOV3 cells (HLAA2 ${ }^{+}, \mathrm{CD}_{147}{ }^{-}$) could not be lysed by the CTLs induced by $\mathrm{CD} 147_{126-134} \mathrm{~L} 2$, and the cytotoxic effect was blocked by HLA-A2 antibody. This demonstrates that the wild-type CD147 $126-134$ peptide is endogenously processed and presented by MCF-7/Adr cells and that the cytotoxic effect occurs in an HLA-A2-restricted manner. Thus, high affinity peptides such as the mutant peptide in this study can bind to MHC complexes with longer half-lives resulting in more efficient $\mathrm{T}$ cell activation. Once activated, $T$ cells are then able to recognize the wild-type antigen peptide on the target cell, including antigens on cancer cells (24).

In conclusion, we identified a novel HLA-A*0201-restricted peptide $\left(\mathrm{CD} 147_{126-134} \mathrm{~L} 2\right)$ and showed that specific CTLs can be elicited by priming T cells with DCs pulsed with this peptide. Moreover, these CTLs are able to specifically and effectively lyse HLA-A2 positive MCF-7/Adr drug-resistant cells which highly express CD147. Therefore, targeting of CTLs against CD147 show promise as an immunotherapy aimed at eliminating drug-resistant cancer cells.

\section{Acknowledgements}

This project was supported by the National Natural Science Foundation of China (grant nos. 31300737 and 31400149), the Scientific and Technological Project of Guangdong Province (grant nos.2014A020212311 and 2016A020215157), and a grant from the Natural Science Foundation of Guangdong Province (grant nos. 2014A030313586 and 2015A030310310).

\section{References}

1. Amiri-Kordestani L, Basseville A, Kurdziel K, Fojo AT and Bates SE: Targeting MDR in breast and lung cancer: Discriminating its potential importance from the failure of drug resistance reversal studies. Drug Resist Updat 15: 50-61, 2012.

2. Muramatsu T: Basigin (CD147), a multifunctional transmembrane glycoprotein with various binding partners. J Biochem 159: 481-490, 2016.

3. Somno A, Anuchapreeda S, Chruewkamlow N, Pata S, Kasinrerk W and Chiampanichayakul S: Involvement of CD147 on multidrug resistance through the regulation of P-glycoprotein expression in K562/ADR leukemic cell line. Leuk Res Rep 6: 33-38, 2016.

4. Zhou S, Liao L, Chen C, Zeng W, Liu S, Su J, Zhao S, Chen M, Kuang Y, Chen X and Li J: CD147 mediates chemoresistance in breast cancer via $\mathrm{ABCG} 2$ by affecting its cellular localization and dimerization. Cancer Lett 337: 285-292, 2013.

5. Pan Y, He B, Song G, Bao Q, Tang Z, Tian F and Wang S: CD147 silencing via RNA interference reduces tumor cell invasion, metastasis and increases chemosensitivity in pancreatic cancer cells. Oncol Rep 27: 2003-2009, 2012.

6. Xu BQ, Fu ZG, Meng Y, Wu XQ, Wu B, Xu L, Jiang JL, Li L and Chen ZN: Gemcitabine enhances cell invasion via activating HAb18G/CD147-EGFR-pSTAT3 signaling. Oncotarget 7: 62177-62193, 2016.

7. Kono K, Iinuma H, Akutsu Y, Tanaka H, Hayashi N, Uchikado Y, Noguchi T, Fujii H, Okinaka K, Fukushima R, et al: Multicenter, phase II clinical trial of cancer vaccination for advanced esophageal cancer with three peptides derived from novel cancer-testis antigens. J Transl Med 10: 141, 2012.
8. Suzuki H, Fukuhara M, Yamaura T, Mutoh S, Okabe N, Yaginuma H, Hasegawa T, Yonechi A, Osugi J, Hoshino M, et al: Multiple therapeutic peptide vaccines consisting of combined novel cancer testis antigens and anti-angiogenic peptides for patients with non-small cell lung cancer. J Transl Med 11: 97 , 2013.

9. Tsang KY, Fantini M, Fernando RI, Palena C, David JM, Hodge JW, Gabitzsch ES, Jones FR and Schlom J: Identification and characterization of enhancer agonist human cytotoxic T-cell epitopes of the human papillomavirus type 16 (HPV16) E6/E7. Vaccine 35: 2605-2611, 2017.

10. Colella TA, Bullock TN, Russell LB, Mullins DW, Overwijk WW, Luckey CJ, Pierce RA, Restifo NP and Engelhard VH: Self-tolerance to the murine homologue of a tyrosinase-derived melanoma antigen: Implications for tumor immunotherapy. J Exp Med 191: 1221-1232, 2000.

11. Shen H, Shao HW, Chen XH, Wu FL, Wang H, Huang ZL, Shen J, Wang T, Zhang WF and Huang SL: Identification of a novel HLA-A2-restricted mutated Survivin epitope and induction of specific anti-HCC CTLs that could effectively cross-recognize wild-type Survivin antigen. Cancer Immunol Immunother 62: 393-403, 2013.

12. Shao H, Lin Y, Wang T, Ou Y, Shen H, Tao C, Wu F, Zhang W, Bo $\mathrm{H}$, Wang $\mathrm{H}$ and Huang S: Identification of peptide-specific TCR genes by in vitro peptide stimulation and CDR3 length polymorphism analysis. Cancer Lett 363: 83-91, 2015.

13. Wang W, Zou L, Zhou D, Zhou Z, Tang F, Xu Z and Liu X: Overexpression of ubiquitin carboxyl terminal hydrolase-L1 enhances multidrug resistance and invasion/metastasis in breast cancer by activating the MAPK/Erk signaling pathway. Mol Carcinog 55: 1329-1342, 2016.

14. Rammensee HG, Bachmann J, Emmerich NP, Bachor OA and Stevanović S: SYFPEITHI: Database for MHC ligands and peptide motifs. Immunogenetics 50: 213-219, 1999.

15. Nijman HW, Houbiers JG, Vierboom MP, van der Burg SH Drijfhout JW, D'Amaro J, Kenemans P, Melief CJ and Kast WM: Identification of peptide sequences that potentially trigger HLA-A2.1-restricted cytotoxic T lymphocytes. Eur J Immunol 23: 1215-1219, 1993.

16. Wijdeven RH, Pang B, Assaraf YG and Neefjes J: Old drugs, novel ways out: Drug resistance toward cytotoxic chemotherapeutics. Drug Resist Updat 28: 65-81, 2016.

17. Chang A: Chemotherapy, chemoresistance and the changing treatment landscape for NSCLC. Lung Cancer 71: 3-10, 2011.

18. Curiel TJ: Immunotherapy: A useful strategy to help combat multidrug resistance. Drug Resist Updat 15: 106-113, 2012.

19. Toole BP and Slomiany MG: Hyaluronan, CD44 and Emmprin: Partners in cancer cell chemoresistance. Drug Resist Updat 11: 110-121, 2008.

20. Walter M, Simanovich E, Brod V, Lahat N, Bitterman H and Rahat MA: An epitope-specific novel anti-EMMPRIN polyclonal antibody inhibits tumor progression. Oncoimmunology 5: e1078056, 2015.

21. Tourdot S, Scardino A, Saloustrou E, Gross DA, Pascolo S, Cordopatis P, Lemonnier FA and Kosmatopoulos K: A general strategy to enhance immunogenicity of low-affinity HLA-A2.1-associated peptides: Implication in the identification of cryptic tumor epitopes. Eur J Immunol 30: 3411-3421, 2000.

22. Engels B, Engelhard VH, Sidney J, Sette A, Binder DC, Liu RB, Kranz DM, Meredith SC, Rowley DA and Schreiber H: Relapse or eradication of cancer is predicted by peptide-major histocompatibility complex affinity. Cancer Cell 23: 516-526, 2013.

23. Valmori D, Fonteneau JF, Lizana CM, Gervois N, Liénard D, Rimoldi D, Jongeneel V, Jotereau F, Cerottini JC and Romero P: enhanced generation of specific tumor-reactive ctl in vitro by selected melan-a/mart-1 immunodominant peptide analogues. J Immunol 160: 1750-1758, 1998.

24. Slansky JE, Rattis FM, Boyd LF, Fahmy T, Jaffee EM, Schneck JP, Margulies DH and Pardoll DM: Enhanced antigen-specific antitumor immunity with altered peptide ligands that stabilize the MHC-peptide-TCR complex. Immunity 13: 529-538, 2000. 